\title{
Uso combinado de sêmen sexado e acasalamento dirigido sobre uma população de bovinos de corte submetida a seleção: estudo de simulação
}

\author{
Haroldo Henrique de Rezende Neves ${ }^{1}$, Roberto Carvalheiro ${ }^{2}$, Luiz Alberto Fries ${ }^{2 *}$, Sandra \\ Aidar de Queiroz ${ }^{3}$
}

\author{
1 Pós-graduação em Genética e Melhoramento Animal - FCAV/Unesp. Bolsista FAPESP. \\ 2 Gensys Consultores Associados S/C Ltda. \\ ${ }^{3}$ Departamento de Zootecnia - FCAV - UNESP - Jaboticabal. Bolsista do CNPq. \\ *In memoriam.
}

RESUMO - Desenvolveu-se um estudo de simulação estocástica com o objetivo de verificar as consequências do uso combinado de acasalamento dirigido e sêmen sexado em uma população de bovinos de corte sob seleção. Simularam-se seis gerações de seleção para três cenários de acasalamento e uso de sêmen sexado. O primeiro cenário foi caracterizado por acasalamento aleatório e uso exclusivo de sêmen convencional. O segundo cenário caracterizou-se pelo uso de acasalamento associativo positivo nas $40 \%$ melhores vacas e acasalamento associativo negativo nas demais, sem uso de sêmen sexado. O terceiro cenário seguiu o mesmo procedimento de acasalamento do segundo, combinando-o com uso de sêmen sexado nas vacas submetidas a acasalamento associativo positivo. O acasalamento associativo positivo teve maior impacto no progresso genético que o uso de sêmen sexado, apesar de ter aumentado a incidência de endogamia na população. O uso de acasalamento associativo negativo foi ineficiente em reduzir a variabilidade dos animais destinados ao abate. O uso combinado de acasalmento associativo positivo e sêmen sexado aumentou a produção de animais geneticamente superiores.

Palavras-chave: acasalamento associativo negativo, acasalamento associativo positivo, seleção, simulação estocástica

\section{Combined use of assortative mating and sexed semen in a simulated beef cattle population under selection}

\begin{abstract}
Stochastic simulation was carried out to access the consequences of combined use of assortative mating and sexed semen in a beef cattle population under selection. Six generations of selection were simulated under three different scenarios of mating strategy and sexed semen use. The first was characterized by random mating and no use of sexed semen. The second was simulated using positive assortative mating (PAM) for the $40 \%$ top dams and negative assortative mating (NAM) for the remainder, with no use of sexed semen. The third followed the mating procedure of the second combined with use of sexed semen for dams under positive assortative mating. Positive assortative mating had more impact on the genetic progress than sexed semen, although it increased inbreeding incidence in the population. The combined use of negative assortative mating breeding was not efficient in reducing genetic variability of inferior offspring. The combined use of positive assortative mating and sexed semen improved production of genetically outstanding animals.
\end{abstract}

Key Words: negative assortative mating, positive assortative mating, selection, stochastic simulation

\section{Introdução}

A sexagem de sêmen é a separação do sêmen em frações enriquecidas com espermatozóides contendo cromossomos sexuais de um dado tipo, o que possibilita a seleção do sexo do futuro embrião e é de grande interesse para diversas atividades pecuárias. Esta tecnologia está disponível comercialmente em vários países, sendo que, no caso de sêmen bovino, o método mais difundido de sexagem é a citometria de fluxo, cujos primeiros resultados apontando sua eficiência foram publicados a partir de 1987 (Johnson et al., 1987; Morell, 1991).

Em vários estudos, tem-se investigado o potencial de uso desta técnica para sistemas de produção de bovinos, sendo apontados como fatores limitantes para sua maior aplicabilidade em larga escala: o custo extra da dose de sêmen sexado, a menor capacidade de fertilização do sêmen sexado em relação ao convencional e a precisão na definição do sexo do futuro produto (Hohenboken, 1999; Seidel, 2003; Madalena \& Junqueira, 2004). 
A sexagem de sêmen permite a manipulação das intensidades de seleção de machos e de fêmeas, mas o impacto de seu uso tem sido considerado maior em sistemas de produção que em programas de melhoramento genético, especialmente em bovinos de corte (Kinghorn et al., 1991; Villanueva et al., 1995).

Outro fator limitante para que o uso de sêmen sexado possa aumentar o ganho genético é a dificuldade de se intensificar a seleção de fêmeas sem comprometer a intensidade de seleção dos machos. Segundo Kinghorn (2003), com modelos simples, seria difícil predizer um ganho extra de mais de $5 \%$ por geração em relação a uma situação com metade dos animais de cada sexo.

Uma alternativa para contornar as limitações do uso de sêmen sexado em programas de melhoramento seria combiná-lo com estratégias de acasalamento dirigido usando mais racionalmente os animais geneticamente superiores, por exemplo, obtendo menos candidatos machos à seleção, mas de modo que estes fossem geneticamente superiores e, concomitantemente, aumentando a intensidade de seleção de fêmeas.

Desenvolveu-se este estudo com os objetivos de avaliar o impacto de algumas estratégias de acasalamento em ciclos repetidos de seleção e acasalamento e investigar as consequências do uso combinado de sêmen sexado e de acasalamento dirigido sobre uma população submetida a seleção.

\section{Material e Métodos}

A população-base foi simulada de modo a ser composta por 200 touros e 5.000 vacas, considerados nãoaparentados, não-selecionados e assumidos como amostra aleatória de uma população conceitualmente infinita.

Simulou-se o acasalamento aleatório das vacas com os touros da população-base, de modo que a primeira geração fosse composta por aproximadamente 2.500 produtos de cada sexo, distribuídos em 100 grupos de contemporâneos.

O processo de seleção contemplou uma reposição anual de $20 \%$ dos reprodutores de cada sexo, por meio da seleção dos melhores 160 machos e 4.000 fêmeas da população-base e dos melhores 40 machos e 1.000 fêmeas de primeira geração, baseada na melhor predição linear não-viesada (BLUP) de seus valores genéticos, obtida pelo software MTDFREML (Boldman et al., 1995), considerando um modelo animal, de modo que os animais selecionados foram acasalados de acordo com algumas estratégias de acasalamento e com uso de sêmen sexado (descritas posteriormente) para produzir a geração seguinte.
Semelhante processo de seleção foi repetido até que os animais da sexta geração fossem produzidos, totalizando 30 mil produtos e 600 grupos de contemporâneos, considerando todos os produtos simulados. De acordo com a estrutura da população descrita, três cenários foram simulados:

- cenário controle: caracterizado pelo acasalamento aleatório dos animais selecionados para pais da próxima geração e uso exclusivo de sêmen convencional;

- acasalamento dirigido e sêmen convencional: caracterizado por uma estratégia de acasalamento dirigido visando aumentar a probabilidade de produzir animais geneticamente superiores e reduzir a variabilidade dos produtos destinados ao abate, com uso de acasalamento associativo positivo para as $40 \%$ melhores vacas (decis 1 a 4, considerando seu valor genético predito) e acasalamento associativo negativo para as demais, usando exclusivamente sêmen convencional;

- acasalamento dirigido e sêmen sexado: caracterizado pelo mesmo procedimento de acasalamento do cenário anterior e pelo uso de sêmen sexado para as $40 \%$ melhores vacas para valor genético predito (inseminando-se as 500 melhores vacas com sêmen sexado de macho e as demais com sêmen sexado de fêmea), além de se usar sêmen convencional para as vacas restantes (decis 5 a 10 para valor genético predito).

Não foi simulado nenhum procedimento para controle de endogamia e não se assumiu diferença entre sêmen sexado e convencional quanto à capacidade de fertilização. Assumiram-se $100 \%$ de fertilidade e 100\% de eficiência no processo de sexagem, o que implica que os resultados obtidos no cenário com uso de sêmen sexado devam ser considerados otimistas.

Em virtude das estratégias simuladas, dos parâmetros de fertilidade e sucesso na sexagem considerados e da política de reposição, analisando-se a proporção de animais selecionados em cada sexo, a intensidade de seleção de machos nos cenários com uso exclusivo de sêmen convencional consistiu, a cada ano, na seleção de 40 machos para reposição entre 2.500 nascidos, ao passo que, no cenário com uso de sêmen sexado, essa relação foi de 40 machos selecionados entre 2.000 nascidos.

Caracterizando a intensidade de seleção de fêmeas nos cenários sem uso de sêmen sexado, foram selecionadas anualmente para reposição 1.000 fêmeas entre 2.500 nascidas. No cenário com uso de sêmen sexado, foram selecionadas 1.000 fêmeas entre 3.000 nascidas.

Para cada repetição, simularam-se observações de uma característica fictícia (Y), uma para cada animal, posterior- 
mente usadas no processo de avaliação genética conduzido para seleção dos animais. Os programas para simular a estrutura dos dados e as observações fenotípicas foram desenvolvidos no software estatístico SAS (SAS, 1998).

Exceto para os animais da população-base, Y foi simulada de acordo com o modelo:

$$
y_{i j}=b_{i}+a_{i j}+e_{i j}
$$

em que $\mathrm{y}_{\mathrm{ij}}=$ observação $\mathrm{Y}$ do animal $\mathrm{j}$ no grupo de contemporâneo (GC) i; $b_{i}=$ efeito do $G_{i}$; $a_{i j}=$ valor genético aditivo (VGA) do animal j no GC i; e $\mathrm{e}_{\mathrm{ij}}=$ termo residual aleatório. Os valores de $\mathrm{e}_{\mathrm{ij}}$ foram independentemente tomados de uma distribuição normal com média zero e variância de 0,6 kg² $(\mathrm{N}(0 ; 0,6))$ e os valores de $b_{i}$ foram tomados de uma distribuição do tipo $\mathrm{N}(0 ; 1,0)$. Os valores genéticos dos animais da população-base foram gerados a partir de uma distribuição $\mathrm{N}(0 ; 0,4)$ e os dos animais das gerações seguintes foram obtidos pela fórmula $a_{i j}=1 / 2\left(a_{s j}+a_{d j}\right)+m_{i j}$, em que $a_{s j}$ e $a_{d j}$ são os valores genéticos verdadeiros do pai e da mãe do animal j e $\mathrm{m}_{\mathrm{ij}}$ é o efeito da segregação mendeliana do animal $\mathrm{j}$, tomado aleatoriamente de uma distribuição normal N $(0 ; 0,2)$.

Os parâmetros usados na simulação reproduziram uma característica medida em kg, com herdabilidade igual a 0,4 e inicialmente seguindo uma distribuição normal com média zero e variância fenotípica de $2,0 \mathrm{~kg}^{2}(\mathrm{~N}(0 ; 2,0))$. Desse modo, a característica $\mathrm{Y}$ deve ser entendida como um critério de seleção em um programa de melhoramento, expresso em ambos os sexos antes da idade reprodutiva, numa população sob seleção.

Os cenários simulados foram comparados com base nos seguintes critérios:

- Estatísticas descritivas (média, máximo, mínimo e variância) dos valores genéticos aditivos verdadeiros (VGA), ao longo das gerações, incluindo progresso genético, o qual foi avaliado pela diferença entre o VGA médio de uma geração e aquele observado na geração anterior.
- Variabilidade da progênie: avaliada pelas distribuições dos valores genéticos e fenotípicos dos animais da G6 e suas respectivas medidas de variância, assimetria e curtose.

- Variabilidade dos produtos destinados ao abate: estimada por meio da variância fenotípica observada nos animais filhos das vacas classificadas como $60 \%$ inferiores, com base na predição de seus valores genéticos por BLUP.

- Produção de machos geneticamente superiores: calculada como sendo o número de machos de G6 com VGA maior que o ponto de truncamento $\mathrm{t}$, sendo $\mathrm{t}=\mu_{\mathrm{vg} 1}+3^{*}\left(\sigma_{\mathrm{vg} 0}\right)$, em que $\mu_{\mathrm{vg} 1}$ representa o VGA médio dos animais do cenário com acasalamento aleatório na sexta geração (G6) e $\sigma_{\mathrm{vg} 0} \mathrm{O}$ desvio-padrão do VGA dos animais da população base.

- Incidência de endogamia: avaliada pela porcentagem de animais endogâmicos (pF) e coeficiente de endogamia dos animais endogâmicos(F) e da população ( $\left.F_{\text {pop }}\right)$, em G6.

Para a validação do processo de simulação estocástico, foram simuladas 30 repetições para cada cenário utilizando-se a média dos valores observados nas repetições para análise dos diferentes critérios. As médias dos cenários foram comparadas pelo teste Tukey $(\mathrm{P}<0,05)$.

\section{Resultados e Discussão}

Na sexta geração simulada (G6), o desvio-padrão genético aditivo foi $22 \%$ maior nos cenários com uso de acasalamento dirigido que o observado no cenário controle (Tabela 1), resultado que pode ser associado à prática de acasalamento associativo positivo nas $40 \%$ melhores vacas, também resultando em maiores valores de VGA máximo para os cenários com uso de acasalamento dirigido. Essa associação seria razoável, admitindo-se que há grande probabilidade de que, a cada geração, os animais oriundos de AP (filhos de pais e mães de EBV mais elevado) sejam selecionados, sobretudo no caso de machos, dada a alta intensidade de seleção neste sexo (Wray \& Goddard, 1994).

Tabela 1 - Valores médios* das estatísticas referentes aos valores genéticos aditivos, incidência de endogamia na população, produção de machos geneticamente superiores e variabilidade dos animais destinados ao abate, considerando os animais da sexta geração em cada cenário ${ }^{\mathrm{D}}$

\begin{tabular}{|c|c|c|c|c|c|c|c|c|c|}
\hline & \multicolumn{4}{|c|}{ Estatísticas dos valores genéticos aditivos (6 ${ }^{a}$ geração) } & \multicolumn{3}{|c|}{ Incidência de endogamiaC } & \multirow[b]{2}{*}{ NMS $^{A}$} & \multirow[b]{2}{*}{$\mathrm{VAA}^{\mathrm{B}}$} \\
\hline Cenário $^{\mathrm{D}}$ & Média & Desvio-padrão & Mínimo & Máximo & $\mathrm{pF}(\%)$ & $F(\%)$ & $\mathrm{F}_{\text {pop }}(\%)$ & & \\
\hline SC1 & $1,32 c$ & $0,60 \mathrm{~b}$ & $-0,76 b$ & $3,46 b$ & $3,21 \mathrm{c}$ & $5,2 a$ & $0,17 b$ & 2c & $1,93 a$ \\
\hline SC2 & $1,55 b$ & $0,73 a$ & $-0,62 \mathrm{a}$ & $4,25 a$ & $7,90 \mathrm{~b}$ & $4,3 b$ & $0,34 \mathrm{a}$ & $41 \mathrm{~b}$ & $1,87 \mathrm{a}$ \\
\hline SC3 & $1,63 a$ & $0,74 a$ & $-0,55 a$ & $4,25 a$ & $8,59 a$ & $3,6 c$ & $0,31 \mathrm{a}$ & $61 \mathrm{a}$ & $1,86 a$ \\
\hline
\end{tabular}

A NMS: machos da sexta geração com VGA maior que $t\left(t=\left(\right.\right.$ VGA médio de SC1 em G6) + $\left(3 *\right.$ DP de VGA em G1) = 1,32 + 3* $\left.(0,4)^{1 / 2}=3,22\right)$.

B VAA: a variabilidade dos animais destinados ao abate foi definida como a variância fenotípica dos bezerros filhos das vacas $60 \%$ inferiores (decis 5 a 10 ).

${ }^{\mathrm{C}}$ Incidência de endogamia na sexta geração: pF é a porcentagem de animais endogâmicos. F e $\mathrm{F}_{\text {pop }}$ são os coeficientes médios de endogamia dos animais endogâmicos e da população, respectivamente, expressos em porcentagem.

DCenários simulados: SC1- uso de acasalamento aleatório, sem uso de sêmen sexado; SC2: acasalamento associativo positivo (AP) para as 40\% melhores vacas e associativo negativo (AN) para as demais, sem uso de sêmen sexado; SC3: política de acasalamento de SC2 e uso de sêmen sexado para as $40 \%$ melhores (sexado de macho nas $10 \%$ melhores e de fêmea nas demais).

* Valores médios referentes a 30 repetições. Valores seguidos por diferentes letras minúsculas diferem entre si $(\mathrm{P}<0,05)$ pelo teste de Tukey. 
O incremento no valor genético aditivo médio nos cenários com acasalamento dirigido, em relação ao VGA médio observado sob acasalamento aleatório, na sexta geração foi de $16 \%$ e $22 \%$ do desvio-padrão fenotípico na geração-base (i.e., $\sqrt{2}$ ), respectivamente, sem uso de sêmen sexado e com uso de sêmen sexado, o que indica aumento do progresso genético, em virtude da associação de acasalamento associativo positivo e sêmen sexado (Tabela 1). O valor mínimo para valores genéticos aditivos foi ligeiramente menor no cenário com acasalamento aleatório, o que também poderia ser associado ao menor progresso genético neste cenário (Tabela 1).

Na sexta geração, a porcentagem de animais endogâmicos (pF) nos dois cenários com acasalamento dirigido foi maior que o dobro daquela observada na situação sob acasalamento aleatório e, considerando toda a população, os coeficientes de endogamia médios também foram maiores com uso de acasalamento dirigido (Tabela 1). Apesar da baixa magnitude dos coeficientes médios de endogamia observados, esses resultados confirmam os de outros estudos de simulação, que também associam o aumento de endogamia ao uso de acasalamento associativo positivo em populações sob seleção (Carvalheiro et al., 2007; Quinton \& Smith, 1995).

Além disso, na seleção baseada em BLUP, mesmo sob acasalamento aleatório, o uso da informação de parentesco aumenta a probabilidade de que animais aparentados sejam selecionados e que a endogamia aumente (Quinton \& Smith, 1995). Contudo, a incidência de endogamia poderia ser controlada com a adequação das estratégias de acasalamento para esse fim, sem grandes perdas na superioridade genética (Meuwissen, 1997; Kinghorn et al., 1999).

Os valores genéticos aditivos médios dos animais aumentaram ao longo das gerações, em decorrência do maior valor genético aditivo médio dos animais de reposição em comparação aos de seus pais (Figura 1).

Com base nas médias das medidas de assimetria e curtose dos valores fenotípicos, pode-se inferir que a distribuição de $\mathrm{Y}$ foi normal na sexta geração, para os três cenários (Tabela 2), e que a similaridade na variabilidade fenotípica entre esses cenários deve-se ao fato de variáveis aleatórias com distribuição normal $\left(\mathrm{e}_{\mathrm{ij}}\right.$, $\mathrm{b}_{\mathrm{i}}$ e $\left.\mathrm{m}_{\mathrm{ij}}\right)$ terem

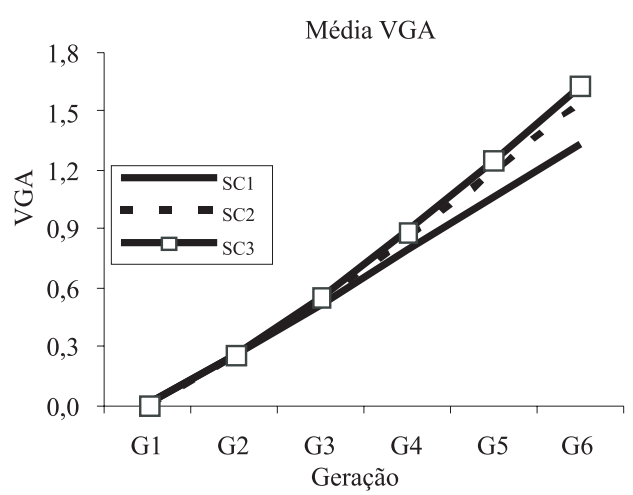

Distribuição VGA

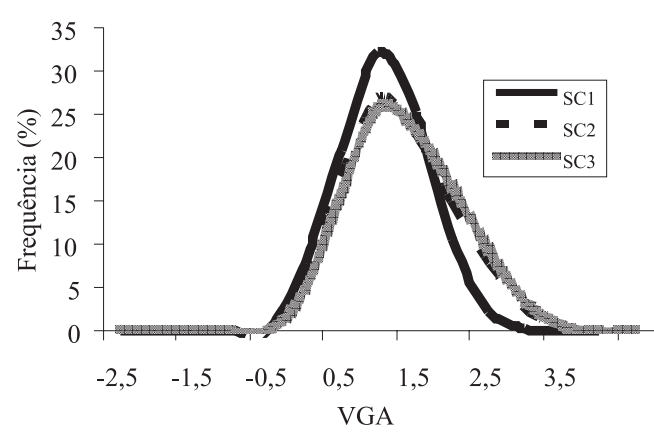

Distribuição VGA-MS
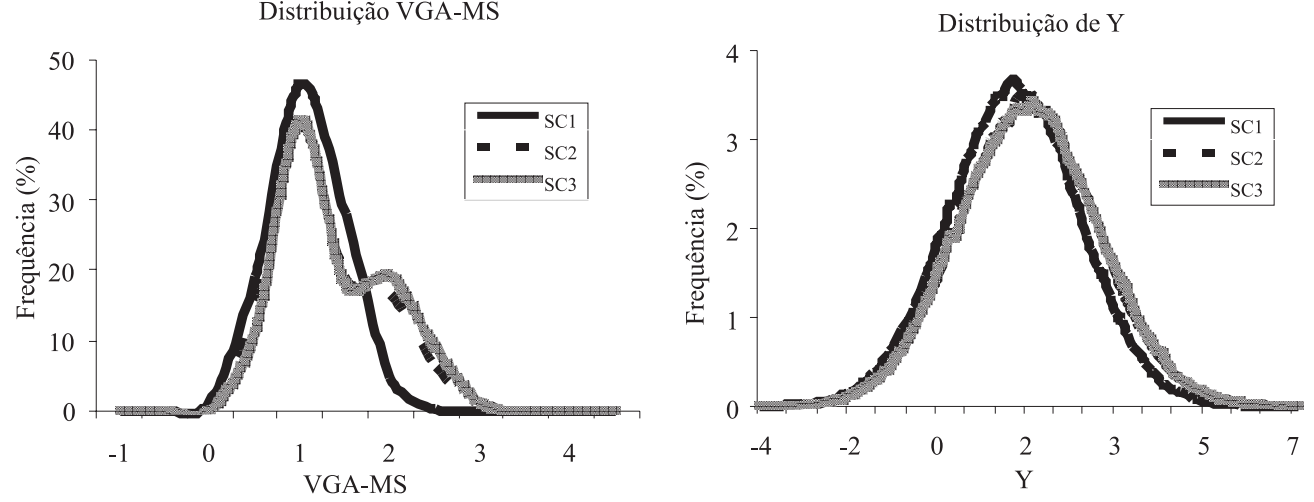

\footnotetext{
A SC1: acasalamento aleatório, sem uso de sêmen sexado; SC2: acasalamento associativo positivo (AP) para as $40 \%$ melhores vacas e associativo negativo (AN) para as demais, sem uso de sêmen sexado; SC3: política de acasalamento de SC2 e uso de sêmen sexado para as $40 \%$ melhores vacas (sexado de macho nas 10\% melhores e de fêmea nas vacas dos decis 2 a 4$)$.
}

Figura 1 - Valores genéticos aditivos (VGA) médios ao longo das gerações (G1 a G6); distribuição de VGA; distribuição de VGA, desconsiderando o efeito de segregação mendeliana (VGA-MS); e observações fenotípicas (Y) na sexta geração para três cenários simulados ${ }^{\mathrm{A}}$. 
determinado a maior parte da variabilidade da característica Y (Figura 1).

A probabilidade de produção de animais extremos inferiores foi similar nos três cenários, o que pode ser explicado pelo fato de $80 \%$ da variabilidade de $\mathrm{Y}$ ter sido determinada aleatoriamente, implicando variabilidade fenotípica similar para os bezerros filhos de vacas submetidas a acasalamento associativo negativo e pouco efeito dessa estratégia de acasalamento no alcance do objetivo ao qual foi inicialmente associada, por exemplo, redução da variabilidade dos animais destinados ao abate (Tabela 1).

As distribuições de valor genético aditivo e de valor genético aditivo sem efeito de segregação mendeliana foram significativamente assimétricas à direita e platicúrticas nos cenários com acasalamento dirigido (Tabela 2), o que poderia ser atribuído ao efeito dessa estratégia de acasalamento. Os valores absolutos das medidas de assimetria e curtose para valor genético aditivo foram menores que aqueles observados para VGA-MS, uma vez que a segregação mendeliana é responsável por metade da variabilidade de valores genéticos aditivos. A distribuição de VGA-MS também se mostrou assimétrica no cenário sob acasalamento aleatório, o que poderia estar relacionado a algum efeito da seleção direcional sobre a distribuição desses valores.

O contraste entre as médias de VGA dos cenários sem uso de sêmen sexado na sexta geração permite associar o uso de acasalamento dirigido (sobretudo de AP, por motivo discutido anteriormente) a um aumento de $17,4 \%$ no VGA médio. Pelo mesmo tipo de contraste, entre os cenários com acasalamento dirigido, percebe-se que a resposta extra

Tabela 2 - Média dos valores de assimetria e curtose do valor genético aditivo (VGA), do valor genético aditivo desconsiderando efeito de segregação mendeliana (VGA-MS) e do valor fenotípico em cada cenário, na sexta geração, com base em 30 repetições

\begin{tabular}{lcccc}
\hline Medida & Cenário $^{\mathrm{A}}$ & VGA & VGA-MS & $\begin{array}{c}\text { Valor } \\
\text { fenotípico }\end{array}$ \\
\hline Assimetria & SC1 & 0,047 & $0,144^{*}$ & $-0,002$ \\
& SC2 & $0,331^{*}$ & $0,672^{*}$ & 0,013 \\
& SC3 & $0,287^{*}$ & $0,568^{*}$ & 0,064 \\
Curtose & SC1 & $-0,035$ & $-0,050$ & 0,004 \\
& SC2 & $-0,137 *$ & $-0,347^{*}$ & 0,062 \\
& SC3 & $-0,274^{*}$ & $-0,668^{*}$ & 0,017 \\
\hline
\end{tabular}

* Valores significativamente diferentes de zero (associados a desvio da normalidade) considerando intervalo de confiança de 95\% (em cada repetição, N=5000).

A SC1: acasalamento aleatório, sem uso de sêmen sexado; SC2: acasalamento associativo positivo (AP) para as $40 \%$ melhores vacas e associativo negativo (AN) para as demais, sem uso de sêmen sexado; SC3: política de acasalamento de SC2 e uso de sêmen sexado para as $40 \%$ melhores (sexado de macho nas $10 \%$ melhores e de fêmea nas demais). decorrente do uso de sêmen sexado foi de 5,16\%, muito próximo do valor mencionado por Kinghorn (2003) ao predizer o ganho extra por geração com uso de sêmen sexado e bastante modesta em comparação à resposta proporcionada pelo acasalamento dirigido (Tabela 1).

Villanueva et al. (1995), em estudo de simulação de núcleos MOET de bovinos de corte, não encontraram benefício ao usarem sêmen sexado para aumentar a intensidade de seleção de fêmeas, em uma característica expressa em ambos os sexos, uma vez que, ao mesmo tempo, a intensidade de seleção de machos diminuiu e a resposta total praticamente não foi alterada.

Neste estudo, o impacto do uso combinado de acasalamento dirigido e sêmen sexado sobre os diferenciais de seleção de machos e fêmeas pode ser avaliado pelas diferenças de VGA médio entre os cenários alternativos e o cenário controle (uso exclusivo de acasalamento aleatório e sêmen convencional) ao longo das gerações. Pelo contraste entre o cenário com acasalamento dirigido sem sêmen sexado e o cenário controle, a resposta extra decorrente do uso de acasalamento dirigido foi praticamente a mesma em ambos os sexos (Figura 2), ao passo que o uso combinado de sêmen sexado e acasalamento dirigido alterou significativamente a resposta medida em cada sexo. Foi possível notar nas primeiras gerações um efeito próximo ao descrito por Villanueva et al. (1995), por exemplo, aumento do ganho genético em fêmeas e decréscimo no ganho em machos.

Na quarta geração, o VGA médio dos machos do cenário com uso combinado de sêmen sexado e acasalamento dirigido praticamente se equiparou ao dos machos do cenário com uso de acasalamento dirigido e sêmen convencional e apresentou maior valor médio que o deste último em G6. Por consequência, a partir de G4, houve maior progresso genético que o observado apenas com o uso de acasalamento dirigido e algum benefício com o uso de sêmen sexado.

Wray \& Goddard (1994) investigaram estratégias de uso de sêmen sexado de fêmea nas matrizes com menor EBV e de sêmen convencional nas demais, de forma a evitar o decréscimo na intensidade de seleção de machos e também predisseram aumento no ganho genético com o uso de sêmen sexado quando as diferenças de intensidade de seleção de machos e de fêmeas eram altas na situação convencional.

Neste estudo, investigou-se a possibilidade de uso de sêmen sexado para aumentar a produção de machos geneticamente superiores a partir das $10 \%$ melhores matrizes e, concomitantemente, intensificar a seleção de fêmeas ao produzirem mais fêmeas filhas de vacas dos decis 2 a 4 , o que permitiu a seleção de novilhas de maior mérito genético no cenário com uso de sêmen sexado, a partir da geração G4 (Figura 2). 
Diferença de VGA médio em cada sexo

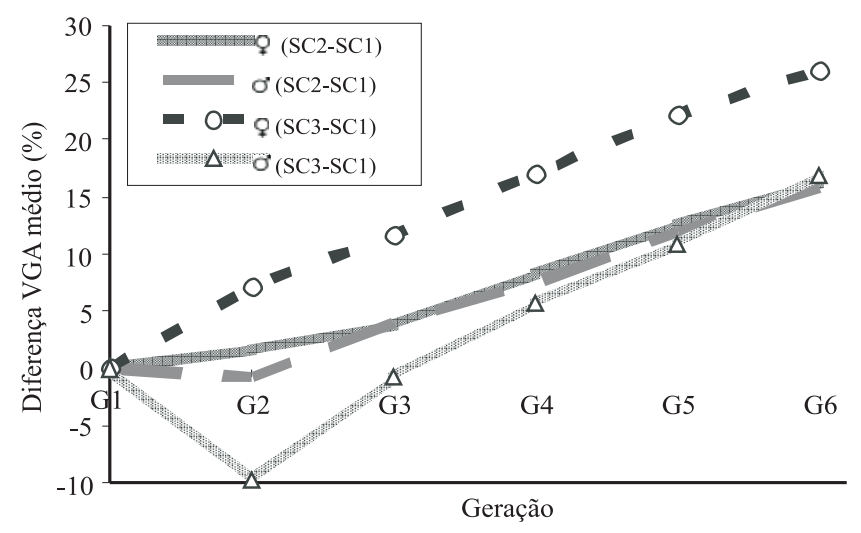

VGA médio das novilhas selecionadas

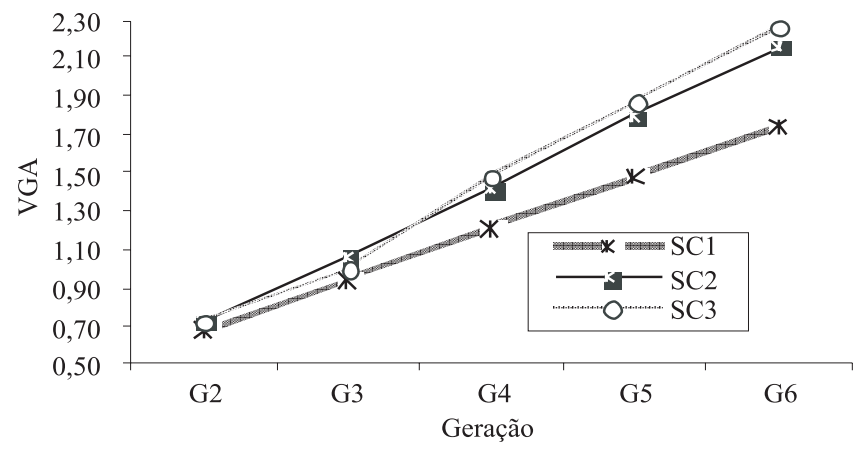

A SC1: acasalamento aleatório, sem uso de sêmen sexado; SC2: acasalamento associativo positivo (AP) para as $40 \%$ melhores vacas (segundo seu valor genético predito) e associativo negativo (AN) para as demais, sem uso de sêmen sexado; SC3: política de acasalamento de SC2 e uso de sêmen sexado para as $40 \%$ melhores (sexado de macho nas 10\% melhores e de fêmea nas vacas dos decis 2 a 4$)$.

Figura 2 - Diferença de valor genético verdadeiro (VGA) médio entre SC2 e SC1 e entre SC3 e SC1(como porcentagem dos valores de SC1) para machos (ぶ) e fêmeas ( $q$ ) de cada geração. Média do valor genético verdadeiro das novilhas selecionadas para reposição, a cada geração, nos cenários simulados ${ }^{\mathrm{A}}$.

Em determinado intervalo de tempo, pode-se esperar que a obtenção de alguma resposta extra por meio do uso de sêmen sexado, sobretudo no caso de características expressas em ambos os sexos, seja alcançada por meio de esquemas alternativos que equacionem o aumento de intensidade de seleção em um dos sexos à manutenção de algum ganho genético no outro sexo.

O uso do acasalamento associativo positivo sem imposição de restrição sobre endogamia implicou em maior resposta à seleção em comparação ao acasalamento aleatório (AA), como também relatado por Quinton \& Smith (1995), em estudo de simulação considerando seleção via BLUP e diferentes estratégias de acasalamento dirigido. Todavia, esses autores enfatizaram que, ao mesmo nível de endogamia, o acasalamento associativo positivo proporcionou respostas inferiores àquelas proporcionadas pelo acasalamento associativo negativo e acasalamento aleatório. Dado o aumento na proporção de animais endogâmicos observada nos cenários com acasalamento dirigido no presente estudo, poder-se-ia esperar uma diminuição na resposta atribuída ao uso do acasalamento associativo positivo.

Todavia, Carvalheiro et al. (2007), simulando a evolução ao longo de 20 anos de uma população fechada e de menor tamanho, verificaram que o uso de acasalamento associativo positivo mediante imposição de restrição sobre endogamia proporcionou maior progresso genético que o acasalamento aleatório. Entretanto, em virtude do menor tamanho efetivo da população simulada, os coeficientes médios de endogamia foram superiores aos obtidos neste estudo.

O número de machos geneticamente superiores (NMS) em G6 foi cerca de 50\% maior no cenário em que se usou sêmen sexado em comparação àquele observado no cenário com uso de acasalamento dirigido e sêmen convencional (Tabela 1). Madalena \& Junqueira (2004) e Hohenboken (1999) referiram-se ao uso de sêmen sexado em apenas parte das fêmeas como uma estratégia para aumentar a produção de animais de maior valor de determinado sexo. O aumento no NMS observado no cenário com uso de sêmen sexado indicaria a eficiência desse tipo de estratégia, no caso com o uso de sêmen sexado nas $10 \%$ melhores vacas para aumentar o número de machos superiores e a proporção de candidatos ao Certificado Especial de Identificação e Produção (CEIP).

A grande diferença entre o NMS nos cenários com acasalamento dirigido, comparado ao do cenário com acasalamento aleatório, também indica o quão vantajoso pode ser o uso do acasalamento associativo positivo para produzir animais geneticamente superiores, como também relatado por Cardoso et al. (2003), que atribuíram o uso de acasalamento dirigido a um aumento de cerca de 70\% no número de animais candidatos ao CEIP.

Conforme mencionado, os resultados deste estudo devem ser considerados otimistas, desse modo, a acurácia na definição do sexo do futuro embrião, a fertilidade e o custo extra do sêmen sexado, assim como o tempo para retorno desse tipo de investimento, devem ser devidamente considerados para uma avaliação acurada da aplicabilidade de sêmen sexado em programas de melhoramento.

\section{Conclusões}

O uso combinado de acasalamento associativo positivo e sêmen sexado permite aumentar o número de machos geneticamente superiores e o ganho genético, o que indica 
benefício no uso dessa estratégia nas melhores vacas do rebanho. O uso de acasalamento associativo positivo aumenta a incidência de endogamia na população. Mais estudos são necessários para avaliar o impacto do uso de sêmen sexado em associação a estratégias de acasalamento dirigido em populações sob seleção, também considerando aspectos econômicos de cada estratégia e o impacto do aumento da incidência de endogamia sobre o progresso genético.

\section{Literatura Citada}

BOLDMAN, K.G.; KRIESE, L.A.; VAN VLECK, L.D. et al. A manual for use of MTDFREML: a set of programs to obtain estimates of variances and covariances (DRAFT). Lincoln: Department of Agriculture/Agriculture Research Service, 1995. 120p.

CARDOSO, V.; ROSO, V.M.; SEVERO, J.L.P. et al. Formando lotes uniformes de reprodutores múltiplos e usando-os em acasalamentos dirigidos, em populações Nelore. Revista Brasileira de Zootecnia, v.32, n.4, p.834-842, 2003.

CARVALHEIRO, R.; NEVES, H.H.R.; QUEIROZ, S.A. et al. Combinando acasalamento associativo positivo e restrição sobre a endogamia visando maior progresso genético. In: REUNIÃO ANUAL DA SOCIEDADE BRASILEIRA DE ZOOTECNIA, 44., 2007, Jaboticabal. Anais... Jaboticabal: Sociedade Brasileira de Zootecnia, 2007. (CD-ROM).

HOHENBOKEN, W.D. Applications of sexed semen in cattle production. Theriogenology, v.52, n.8, p.1421-1433, 1999.

JOHNSON, L.A.; FLOOK, J.P.; LOOK, M.V. Flow cytometry of X and $\mathrm{Y}$ chromosome-bearing sperm for DNA using an improved preparation method and staining with HOECHST 33342. Gamete Research, v.17, n.3, p.203-212, 1987.

KINGHORN, B.P. Options for genetic improvement of Bali cattle - Assessing the strengths and weaknesses of alternative strategies option 1. Full program with all technologies and facilities available. In: ENTWISTLE, K.; LINDSAY, D.R. (Eds.) Strategies to improve Bali cattle in Eastern Indonesia. Canberra: ACIAR, 2003. p.58-71.

KINGHORN, B.P.; SHEPHERD, R.K.; WOOLLIAMS, J.A. An index of estimated breeding value, parental coancestry and progeny inbreeding to help maximize genetic gains. In.: ASSOCIATION FOR THE ADVANCEMENT OF ANIMAL BREEDING AND GENETICS CONFERENCE, 13., 1999, Mandurah. Proceedings... Mandurah: AAABG, 1999. p.412-415.

KINGHORN, B.P.; SMITH, C.; DEKKERS, J.C.M. Potential genetic gains with gamete harvesting and in vitro fertilization in dairy cattle. Journal of Dairy Science, v.74, n.2, p.611-622, 1991.

MADALENA, F.E.; JUNQUEIRA F.S. The value of sexed bovine semen. Journal of Animal Breeding and Genetics, v.121, n.4, p.253-259, 2004.

MEUWISSEN, T.H.E. Maximizing the response of selection with a predefined rate of inbreeding. Journal of Animal Science, v.75, n.4, p.934-940, 1997.

MORELL, J.M. Application of flow cytometry to artificial insemination: a review. The Veterinary Record, v.129, n.17, p.375-378, 1991.

QUINTON, M.C.; SMITH, C. Comparison of evaluation-selection systems for maximizing genetic response at the same level of inbreeding. Journal of Animal Science, v.73, n.8, p.2208-2212, 1995.

STATISTICAL ANALYSIS SYSTEM - SAS. SAS/STAT: user's guide. version 6.12, 4.ed. Cary: SAS Institute, 1998. 842p.

SEIDEL JR., G.E. Economics of selecting for sex: the most important genetic trait. Theriogenology, v.59, n.2, p.585-598, 2003.

VILLANUEVA, B.; WOOLLIAMS, J.A.; SIMM, G. Strategies for controlling rates of inbreeding in MOET nucleus schemes for beef cattle. Genetics Selection Evolution, v.27, n.4, p.347363, 1995

WRAY, N.R.; GODDARD, M.E. MOET breeding schemes for wool sheep. 1. Design alternatives. Animal Production, v.59, n.1, p.71-86, 1994 . 